\title{
AN INVESTIGATION OF THE TRANSMISSION, REFLECTION AND ABSORPTION OF SOUND BY DIFFERENT MATERIALS.
}

By F. R. WATSON.

$\mathrm{T}$ HE experiments on the transmission of sound were performed with the following arrangement of apparatus. ${ }^{1}$ The source of sound was an adjustable whistle blown by air from a constant pressure tank and mounted at the focus of a specially constructed parabolic reflector with a focal length of nine inches and an aperture of five feet. This was placed in front of an open doorway so that the sound, which proceeded in a large parallel bundle from the reflector, could pass through the doorway into another room. The receiver of sound, a Rayleigh resonator, was mounted in the other room in the path of the sound symmetrically opposite the reflector and doorway and measured the intensity of the transmitted sound.

The resonator used was a modification of Rayleigh's original design. ${ }^{2}$ It consisted of a horizontal brass tube closed at one end by an adjustable piston. A mica disc was suspended by a quartz fiber at an angle of $45^{\circ}$ with the axis of the tube. When the sound of the whistle reached the resonator it set up a back-and-forth surging of the air in the resonator and caused the mica disc, which was placed at a loop, to rotate. This action is in accordance with the general principle that any flat object in a current of air tends to set itself at right angles to the current. The amount of rotation was measured by means of a lamp and scale in connection with a mirror which was attached to the suspended system above the mica disc.

The readings on the scale are proportional, for small angles of rotation of the disc, to the intensity of the sound. This is shown as follows. The moment $M$ of the couple turning the disc may be proven ${ }^{3}$ to be

$$
M=k W^{2} \sin 2(\theta-\varphi),
$$

where $W$ is the velocity of the steam, $\theta$ is the angle of repose between the direction of the stream and the normal to the disc, $\varphi$ is the angle of

${ }^{1}$ Phys. Rev., Vol. V., p. 342 , I9r 5.

${ }^{2}$ Phil. Mag., Vol. I4, p. I86, I882.

${ }^{3}$ W. König, Wied. Ann., Vol. 43, p. 5 r, I89r. 
deflection, and $k$ is a constant. In case the stream is not steady but alternating, as it would be in the case of the vibrating air in the resonator, $W^{2}$ may be replaced ${ }^{1}$ by the mean value of $W^{2}$. The intensity, $I$, of the sound setting up the vibrations in the resonator is proportional to the square of the velocity, ${ }^{2}$ so that

$$
M=k_{1} I \sin 2(\theta-\varphi) .
$$

Finally the turning couple $M$ becomes equal for equilibrium to the restoring couple set up by the twisted quartz fiber and this latter couple is proportional for small angles of rotation to the angle of rotation $\varphi$, or

$$
M=k_{2} \varphi \text {. }
$$

Comparing the intensities of two sounds we get

$$
\frac{I_{1}}{I_{2}}=\frac{\varphi_{1}}{\varphi_{2}} \cdot \frac{\sin 2\left(\theta-\varphi_{2}\right)}{\sin 2\left(\theta-\varphi_{1}\right)} .
$$

In the experimental observations, $\varphi$ was not measured directly; since the scale readings are proportional to $\tan 2 \varphi$, the scale being plane and the angle of deflection being doubled by the reflection of the spot of light from the mirror. Calculations for the data taken show that the ratios

and

$$
\frac{\tan 2 \varphi_{1}}{\tan 2 \varphi_{2}}
$$

$$
\frac{\varphi_{1} \sin 2\left(\theta-\varphi_{2}\right)}{\varphi_{2} \sin 2\left(\theta-\varphi_{1}\right)}
$$

differ about 2 per cent. for the maximum angle of deflection, $\mathrm{II}^{\circ}$. Therefore, as stated, the readings on the scale may be taken as proportional to the intensity of the sound.

Measurements were taken, first, through the open doorway, then with one panel of material placed over the doorway, then two panels and finally three panels; the deflection of the resonator being noted for each case. Considerable trouble was experienced in getting steady deflections of the resonator. This was finally overcome to a great extent by arranging a delicate adjustment for keeping constant the flow of air to the whistle, and also by building a small house with a glass window for the observer. Any movement of articles or air in the room changed the deflection of the resonator so that rigid observance of immovability of objects was necessary. The samples to be tested were mounted on similar frames of one-inch cypress strips and fastened over the open

1 Rayleigh, Th. of Sound, Vol. II., p. 44.

${ }^{2}$ Rayleigh, Th. of Sound, Vol. II., p. r6, and Zernov, Ann. der Phys., Vol. 26, p. 79, I908. 
VoL. VII.] TRANSMISSION OF SOUND BY DIFFERENT MATERIALS. 127
No. I.

doorway by two ropes. A strip of hairfelt was mounted around the woodwork of the doorway to prevent sound leaking through at the edges. Preliminary measurements were carried on for some time to get the apparatus and method of taking observations in satisfactory shape. On December 30, two complete sets of observations were taken, the average of these being used to obtain the comparative values of the transmission powers of the different materials. Table I. gives the results obtained.

TABLE I.

Transmission of Sound.

\begin{tabular}{|c|c|c|c|c|c|c|c|c|}
\hline \multirow{2}{*}{$\begin{array}{c}\text { Material. } \\
\text { Thickness in Layers. }\end{array}$} & \multicolumn{4}{|c|}{$\begin{array}{c}\text { Deflection of Resonator in } \\
\text { Centimeters. }\end{array}$} & \multicolumn{4}{|c|}{ Average Deflection. } \\
\hline & $\circ$ & $\mathbf{I}$ & 2 & 3 & o & I & 2 & 3 \\
\hline Open doorway $\ldots \ldots \ldots \ldots\}$ & $\begin{array}{l}40.3 \\
38.5\end{array}$ & & & & 39.4 & & & \\
\hline $1 / 2^{\prime \prime}$ hairfelt. $\left.\ldots \ldots \ldots \ldots \ldots\right\}$ & & $\begin{array}{l}23.0 \\
22.3\end{array}$ & $\begin{array}{l}15.3 \\
15.5\end{array}$ & $\begin{array}{r}10.8 \\
9.9\end{array}$ & & 22.6 & 15.4 & 10.4 \\
\hline $1 / 4^{\prime \prime}$ cork board. & & $\begin{array}{l}7.7 \\
8.1\end{array}$ & $\begin{array}{l}3.6 \\
3.9\end{array}$ & $\begin{array}{l}2.9 \\
2.9\end{array}$ & & 7.9 & 3.75 & 2.9 \\
\hline $3 / 4^{\prime \prime}$ cork board. . & & $\begin{array}{l}1.1 \\
1.2\end{array}$ & $\begin{array}{l}2.1 \\
2.0\end{array}$ & $\begin{array}{l}1.0 \\
0.7\end{array}$ & & 1.15 & 2.05 & 0.85 \\
\hline $1 / 4^{\prime \prime}$ paper-lined hairfelt.... $\}$ & & $\begin{array}{l}5.7 \\
4.3\end{array}$ & $\begin{array}{l}22.3 \\
21.1\end{array}$ & $\begin{array}{l}4.4 \\
3.2\end{array}$ & & 5.0 & 21.7 & 3.8 \\
\hline $3 / 4 "$ paper-lined hairfelt.... $\}$ & & $\begin{array}{l}7.1 \\
5.9\end{array}$ & $\begin{array}{l}2.0 \\
1.9\end{array}$ & $\begin{array}{l}0.5 \\
0.3\end{array}$ & & 6.5 & 1.95 & 0.4 \\
\hline $3 / 4^{\prime \prime}$ flax board..... & & $\begin{array}{l}2.2 \\
2.3\end{array}$ & $\begin{array}{l}0.5 \\
0.6\end{array}$ & $\begin{array}{l}0.1 \\
0.1\end{array}$ & & 2.25 & 0.55 & 0.1 \\
\hline $1 / 4^{\prime \prime}$ pressed fiber. ....... & & $\begin{array}{l}0.4 \\
0.25\end{array}$ & & & & 0.32 & & \\
\hline $3 / 4^{\prime \prime}$ pressed fiber. . . . . . . . & & 0.2 & & & & 0.2 & & \\
\hline
\end{tabular}

Table II. gives the calculated percentages of the sound transmitted and the sound stopped, it being assumed that the open doorway transmits Ioo per cent. or, that it stops o per cent.

The data of Table II. are shown in the form of curves in Fig. I. Inspection of these curves shows that $1 / 2$ in. hairfelt stops less sound than the other materials, one layer stopping only 43 per cent. Next comes the $1 / 4$ in. cork board which stops 80 per cent. for one layer and 90.5 per cent. and 92.6 per cent. for two and three layers respectively. This is followed by the $3 / 4$ in. paper covered hairfelt, the $3 / 4$ in. flax board and finally the $1 / 4$ in. pressed fiber, one layer of which stops practically all the sound. These values do not tell the whole story concerning the acoustical efficiency of the materials, since other qualities must also be considered. The pressed fiber, for instance, is of little value acoustically because its sound absorbing power is very small. 
TABLE II.

Transmission of Sound Through Different Materials.

\begin{tabular}{|c|c|c|c|c|c|c|c|c|}
\hline \multirow{3}{*}{$\begin{array}{c}\text { Material. } \\
\text { Thickness in Layers....... }\end{array}$} & \multicolumn{8}{|c|}{ Percentage of Sound. } \\
\hline & \multicolumn{4}{|c|}{ Transmitted. } & \multicolumn{4}{|c|}{ Stopped. } \\
\hline & o & $\mathbf{I}$ & 2 & 3 & $\circ$ & I & 2 & 3 \\
\hline 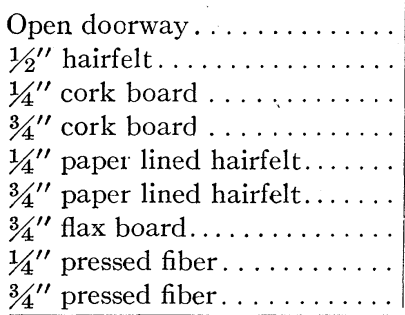 & 100 & $\begin{array}{c}57.0 \\
20.0 \\
2.9 \\
13.0 \\
1.7 \\
5.7 \\
0.08 \\
0.05\end{array}$ & $\begin{array}{c}39.0 \\
9.5 \\
5.2 \\
55.0 \\
0.5 \\
0.14\end{array}$ & $\begin{array}{c}26.0 \\
7.4 \\
2.2 \\
9.6 \\
0.1 \\
0.02\end{array}$ & 0 & $\begin{array}{l}43.0 \\
80.0 \\
97.1 \\
87.0 \\
98.3 \\
94.3 \\
99.9 \\
99.9\end{array}$ & $\begin{array}{l}61.0 \\
90.5 \\
94.8 \\
45.0 \\
99.5 \\
99.8\end{array}$ & $\begin{array}{l}74.0 \\
92.6 \\
97.8 \\
90.4 \\
99.9 \\
99.9\end{array}$ \\
\hline
\end{tabular}

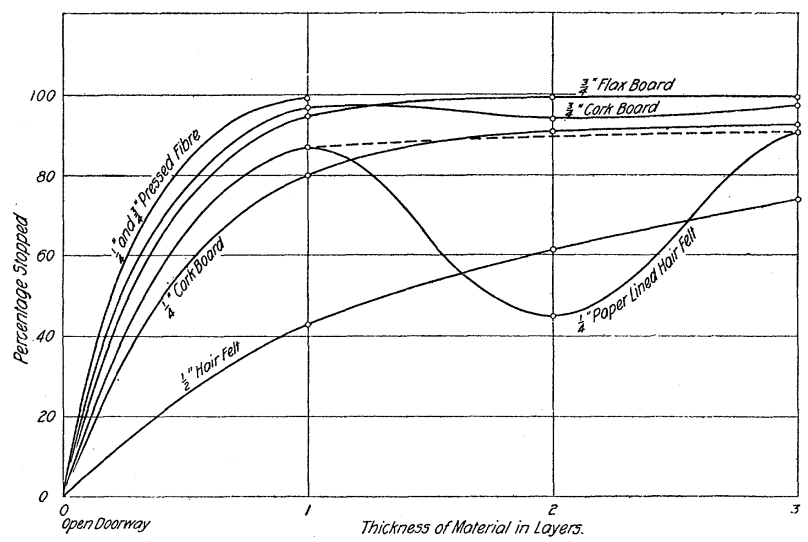

Fig. 1.

Percentage of sound stopped by materials.

Curves showing the percentage of sound stopped by different materials.

The curves for the $1 / 4$ in. paper-lined hairfelt show that this sample acts differently than the others. Two layers of this material stop less sound than one layer. Repeated measurements gave the same puzzling result. The $3 / 4$ in. cork board shows the same phenomenon, but to a less degree. After some consideration, it was decided to investigate other acoustical properties of the samples to see if additional data would explain this anomalous transmission.

If incident sound falls on a material, three things may happen. The sound may be partly reflected, partly absorbed and the rest transmitted. If these three fractions are added together, they must equal the incident sound, or 


$$
T+A+R=I=\text { Ioo per cent. }
$$

Therefore to know what happens to the incident sound it is necessary to determine the amounts reflected, absorbed and transmitted. On considering the case of the paper-lined hairfelt in the light of this reasoning, it was decided to attempt to measure the reflection of sound.

\section{REFLECTION OF SOUND.}

By moving the parabolic reflector off to one side, the sound was sent obliquely toward the open doorway where it was reflected by the hairfelt and then passed to the Rayleigh resonator which had been moved into the same room with the reflector and placed so as to be directly in the path of the reflected sound. The observer, as in the transmission tests, stationed himself inside the small house and read the deflection of the

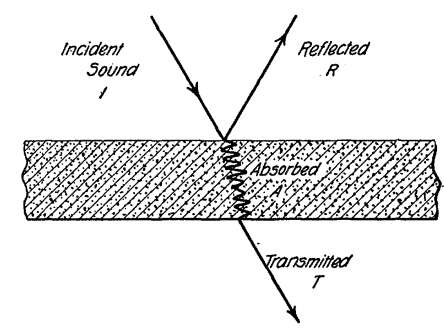

Fig. 2.

Action of a material in reflecting, absorbing and transmitting sound.

resonator through the glass window. A small portion of sound was reflected from the sides of the doorway so that, even with no material over the open door space, the resonator gave a small deflection. This was taken as the zero deflection for the other readings. The deflection for Ioo per cent. reflection was arbitrarily taken to be the largest deflection obtained, namely, the deflection given by one layer of $3 / 4$ in. cork board. This value is doubtless too small, but probably not much in error, especially when only comparative values are being considered.

The average of two sets of observations on the reflection of sound from the materials is given in Table III. and in curves in Fig. 3. The interpretation of the results is best realized by combining curves from Figs. I and 3. Thus, for $1 / 2$ in. hairfelt in Fig. 4 , it is seen that the curve for the reflected sound follows very closely the curve for the stopped sound. Consideration of Fig. 2 shows that the sound which is stopped by the material is reflected and absorbed.

The amounts of reflected, absorbed and transmitted sound are thus 
TABLE III.

Reflection of Sound by Different Materials.

\begin{tabular}{|c|c|c|c|c|c|c|c|c|}
\hline \multirow{2}{*}{$\frac{\text { Material. }}{\text { Thickness in Layers. }}$} & \multicolumn{4}{|c|}{$\begin{array}{c}\text { Deflection of Resonator in } \\
\text { Centimeters. }\end{array}$} & \multicolumn{4}{|c|}{$\begin{array}{l}\text { Percentage of Sound } \\
\text { Reflected. }\end{array}$} \\
\hline & o & $\mathbf{x}$ & 2 & 3 & $\circ$ & $\mathbf{I}$ & 2 & 3 \\
\hline Open doorway. & 3.9 & & & & 0 & & & \\
\hline $1 / 2^{\prime \prime}$ hairfelt.... & & 4.9 & 6.6 & 10.5 & & 19 & 25 & 40 \\
\hline $1 / 4^{\prime \prime}$ cork board.. & & 15.7 & 22.0 & 22.6 & & 61 & 85 & 87 \\
\hline $3 / 4^{\prime \prime}$ cork board. . . . . . . . & & 25.9 & 21.2 & 22.1 & & 100 & 82 & 85 \\
\hline $1 / 4^{\prime \prime}$ paper lined hairfelt... & & 20.7 & 5.9 & 10.0 & & 80 & 23 & 39 \\
\hline $3 / 4^{\prime \prime}$ paper lined hairfelt... & & 10.4 & 6.6 & 9.3 & & 40 & 25 & 36 \\
\hline $3 / 4^{\prime \prime}$ flax board . . . . . . . & & 22.5 & 20.0 & 20.0 & & 87 & 77 & 77 \\
\hline $1 / 4^{\prime \prime}$ pressed fiber. . . . . . . & & 23.2 & & & & 90 & & \\
\hline
\end{tabular}

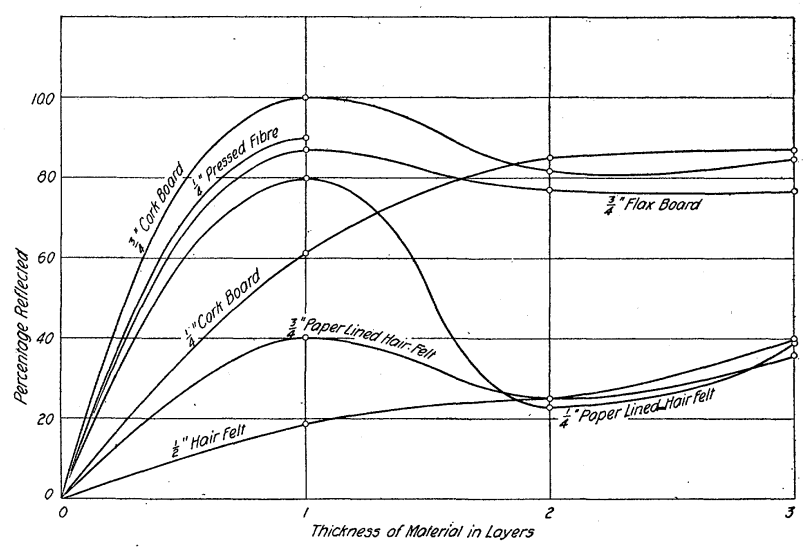

Fig. 3. Percentage of Sound Reftected by Materials

Fig. 3.

Curves showing the percentage of sound reflected by different materials.

easily shown in Fig. 4. The amounts of sound reflected and absorbed increase with the thickness, but the transmission decreases. It should be remembered that the absolute values for the absorption and reflection are doubtless in error but that the comparative values are in correct proportion.

The curves for the $1 / 4$ in. paper-lined hairfelt are shown in Fig. 5. The two curves of reflection and transmission follow each other closely. It is interesting to note how the absorption increases uniformly although the transmission and reflection both vary. The probable cause for the anomalous reflection and transmission, as will be discussed later, lies in the vibration of the material due to resonance. Certain thicknesses of the material vibrate vigorously under the action of the sound and thus 
Vol. VII.] TRANSMISSION OF SOUND BY DIFFERENT MATERIALS. I 3 I
No. I.

create sound waves on the further side of the material. This explanation is advanced also by Weisbach ${ }^{1}$ who made a similar test but with different apparatus and method.

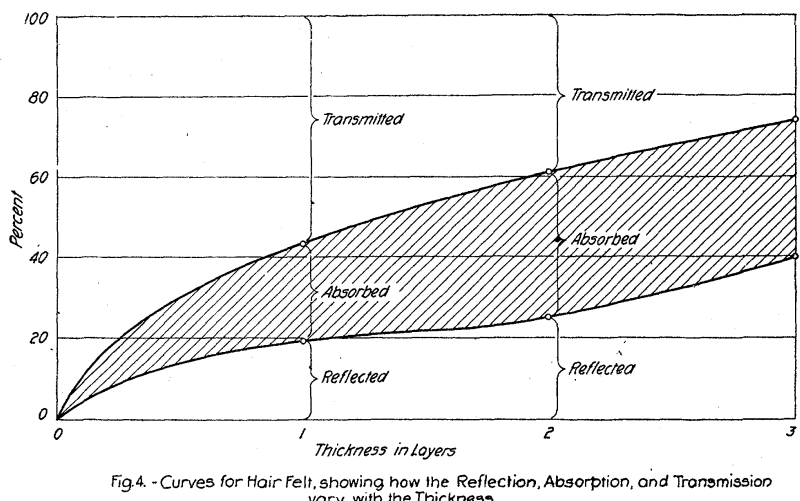

Fig. 4.

Curves for hairfelt, showing how the reflection, absorption and transmission vary with the thickness.

Discussion OF Results.

The transmission of sound of constant pitch depends on at least three qualities of the transmitting material;-its porosity, density and elasticity. Porous bodies transmit sound in much the same proportion that

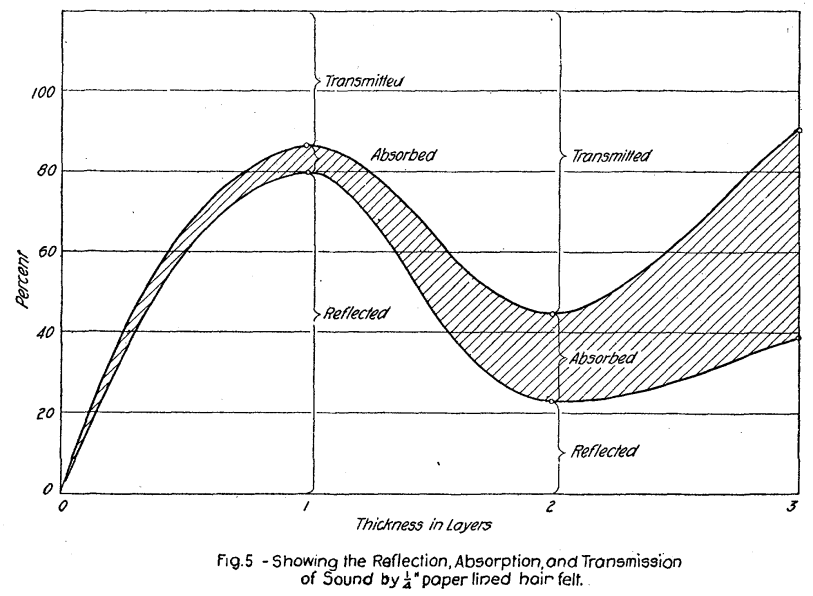

Fig. 5.

Showing the reflection, absorption and transmission of sound by $1 / t^{\prime \prime}$ paper-lined hairfelt.

1 "Versuche über Schalldurschlassigkeit, Schallreflexion und Schallabsorption," Annalen der Physik, Vol. 33, p. 763, I9 Iо. 
they transmit air. ${ }^{1}$ This is why hairfelt transmits more sound than the other samples. Density also plays a part. Two samples stop sound in proportion to their densities, other conditions being equal. ${ }^{2}$ Thus the pressed fiber stops more sound than the same thickness of cork because it is heavier. Finally, an elastic body may transmit sound if it happens to be in tune with the source of sound so as to vibrate. To make this clear, consider the material to form a wall in the path of the sound and imagine it to vibrate exactly as the air would if the material were not present. Under these circumstances, there would be no reflection but only transmission of sound. From the results obtained it seems probable that two layers of paper lined hairfelt approximate to such a vibration.

In case the pitch of the sound varies, porous walls and elastic walls reflect high pitched sounds in greater degree than low pitched ones. ${ }^{3}$

LABORATORY OF PHYSICS, UNIVERSITY OF ILLINOIS.

1 Tufts, Amer. Jour. of Science, Vol. 2, p. 357, I90r.

2 Jäger, "Zur Theorie des Nachhalls," Sitzber. der Kaiserl. Akad. der Wissenschaften in Wien, Math-naturw. Klasse; Bd. CXX., Abt. II $a$, Mai, I9II.

${ }^{3}$ Jäger, loc. cit. 